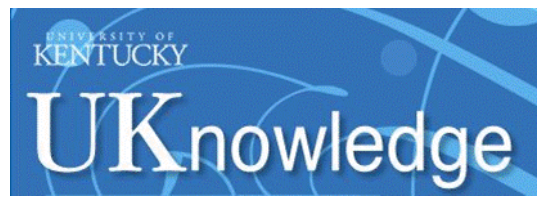

University of Kentucky

UKnowledge

Center for Health Services Research Faculty

Publications

Center for Health Services Research

5-16-2017

\title{
Serious Mental Illness Among Young Adult Women Who Use Drugs in the Club Scene: Co-Occurring Biopsychosocial Factors
}

\author{
Maayan Lawental \\ University of South Florida \\ Hilary L. Surratt \\ University of Kentucky, hilary.surratt@uky.edu \\ Mance E. Buttram \\ Nova Southeastern University \\ Steven P. Kurtz \\ Nova Southeastern University
}

Follow this and additional works at: https://uknowledge.uky.edu/chsr_facpub

Part of the Health Services Research Commons, Psychiatric and Mental Health Commons, Psychology Commons, Substance Abuse and Addiction Commons, and the Women's Health Commons Right click to open a feedback form in a new tab to let us know how this document benefits you.

\section{Repository Citation}

Lawental, Maayan; Surratt, Hilary L.; Buttram, Mance E.; and Kurtz, Steven P., "Serious Mental Illness Among Young Adult Women Who Use Drugs in the Club Scene: Co-Occurring Biopsychosocial Factors" (2017). Center for Health Services Research Faculty Publications. 7.

https://uknowledge.uky.edu/chsr_facpub/7

This Article is brought to you for free and open access by the Center for Health Services Research at UKnowledge. It has been accepted for inclusion in Center for Health Services Research Faculty Publications by an authorized administrator of UKnowledge. For more information, please contact UKnowledge@lsv.uky.edu. 


\section{Serious Mental Illness Among Young Adult Women Who Use Drugs in the Club Scene: Co-Occurring Biopsychosocial Factors}

Digital Object Identifier (DOI)

https://doi.org/10.1080/13548506.2017.1330545

Notes/Citation Information

Published in Psychology, Health \& Medicine, v. 23, issue 1, p. 82-88.

(C) 2017 Informa UK Limited, trading as Taylor \& Francis Group

The copyright holder has granted the permission for posting the article here.

This is an Accepted Manuscript of an article published by Taylor \& Francis in Psychology, Health \& Medicine on 16 May 2017, available online: http://www.tandfonline.com/10.1080/

13548506.2017.1330545. 


\title{
Serious mental illness among young adult women who use drugs in the club scene: co-occurring biopsychosocial factors
}

\author{
Maayan Lawental $^{\mathrm{a}, \mathrm{b}}$, Hilary L. Surratt ${ }^{\mathrm{c}}$, Mance E. Buttram ${ }^{\mathrm{d}}$, and Steven P. Kurtz ${ }^{\mathrm{d}}$ \\ aSchool of Social Work, College of Behavioral and Community Sciences, University of South \\ Florida, Tampa, FL, USA \\ bSchool of Social Work, University of Haifa, Haifa, Israel \\ ${ }^{\circ}$ Center for Health Services Research, University of Kentucky, Lexington, KY, USA \\ ${ }^{d}$ Center for Applied Research on Substance Use and Health Disparities, Nova Southeastern \\ University, Miami, FL, USA
}

\begin{abstract}
Young women who regularly attend nightclubs are at risk for numerous health and social consequences, including mental distress, sexual and physical victimization and substance dependence. This paper uses a biopsychosocial framework to examine co-occurring mental health problems, victimization, substance dependence, sexual risk and physical pain among a sample of young women who use drugs $(\mathrm{N}=222)$ in Miami's club scene. The majority of women were under 24 years old, Hispanic, and identified as heterosexual. Almost all the women reported past 90-day use of alcohol, ecstasy/MDMA, marijuana, cocaine and prescription opioids and benzodiazepines; $32 \%$ of women reported being in a monogamous relationship while $41.9 \%$ reported having three or more sexual partners in the past 90 days; $65.3 \%$ met DSM-IV criteria for substance dependence; 60.4\% met DSM-IV criteria for serious mental illness (SMI) and 59.9\% were victimized as minors. Women who had SMI had higher odds of substance dependence, concurrent physical pain, three or more sexual partners in the past 90 days, childhood victimization and severe abuse-related trauma. The high levels of interconnected mental health, victimization, trauma, physical pain, substance dependence and sexual risk factors observed are underreported in the literature, as young women club scene participants appear to be more similar to other marginalized drug-involved populations than previously considered. While further research is needed, it appears these young women are in great need of outreach for primary health, mental health, HIV prevention, increased social support and substance abuse treatment services.
\end{abstract}

\section{Keywords}

Club drugs; substance use; women; sexual risk; victimization; serious mental illness (SMI); pain; social support; biopsychosocial

CONTACT Maayan Lawental, mlawental@usf.edu.

Disclosure statement

No potential conflict of interest was reported by the authors. 


\section{Introduction}

Adults with serious mental illness (SMI) engage in high rates of drug use and risky sexual behaviors that are linked to higher rates of HIV and other sexually transmitted and bloodborne infections, (Surratt, Kurtz, Chen, \& Mooss, 2011). Women who use drugs are at greater risk than men of having multiple partners and unprotected sex (Meade \& Sikkema, 2005), being victimized (Wechsberg, 2012), developing substance dependence and SMI, contracting HIV and sexually transmitted infections (Buttram, Surratt, \& Kurtz, 2014), and having limited social support and access to health and social services (Greenfield et al., 2007; Wechsberg, 2012). With the close relationship between mental and physical health well documented (Ferro, 2016), women also report higher incidence of non-cancer chronic pain linked to psychological distress (Jamison, Butler, Budman, Edwards, \& Wasan, 2010), and receiving and misusing opioid prescriptions (Parsells et al., 2008), findings that are partially attributed to women's limited access to services (Simoni-Wastila, 2000). It stands to reason, therefore, that co-occurring SMI and drug use is a complex phenomenon that must be viewed within the gendered-social-ecological context in which it occurs.

Studies have explored the intersection of drug use and sexual risk within the social context of nightclubs (Remy et al., 2013) where the risk of contracting HIV and other infectious diseases has been a cause for concern (Kelly \& Parsons, 2007). Although much of this research has focused on lesbian, gay, bi-sexual, transgender and queer communities, several studies highlight the vulnerability of women in the club scene (Buttram \& Kurtz, 2015).

The literature describing drug use and related health and social consequences among young adult women in the club culture is limited. While studies concerning drug use and risky sexual behaviors are prevalent, studies exploring SMI and contributing factors are less common, limiting our ability to design and implement effective interventions to mitigate risks. This study seeks to bridge the gap by using a biopsychosocial framework to examine whether SMI among young women in the club scene is linked to co-occurring substance dependence, victimization, physical pain, trauma, sexual risk and lack of social support.

\section{Materials and methods}

Data are drawn from baseline assessments conducted as part of a behavioral intervention trial for young adults who use club drugs (e.g. ecstasy/MDMA, GHB, ketamine, LSD, methamphetamine, cocaine), and misuse prescription medications (Kurtz, Surratt, LeviMinzi, \& Mooss, 2011) in the context of the electronic dance music club scene in Miami. A total of 498 participants completed baseline health and social risk assessments. For a full description of the site, inclusion exclusion criteria, recruitment and sampling procedures see Kurtz, Buttram, \& Surratt, 2017. A subset of 222 women who reported recent heterosexual behavior is the focus of this paper.

Data was collected using the Global Appraisal of Individual Needs (GAIN; Dennis, Feeney, Stevens, \& Bedoya, 2006) expanded to include questions on non-medical use of psychoactive prescription medications. For psychometric properties please see Kurtz et al., 2017;. SMI was measured using the self-report General Mental Distress Scale (GMDS), 
which is comprised of past year DSM-IV symptoms counts for 25 items -9 for depression (Cronbach's alpha among this sample $=.87$ ), 12 for anxiety (alpha $=.88$ ), and 4 for somatic disorders (alpha $=.81$ ). This scale is reducible to classifications indicating clinical significance (subclinical/moderate/severe) and was further dichotomized into severe ( 7 or more symptoms)/not severe. Substance dependence was assessed as endorsement of 3 or more DSM-IV dependence criteria (e.g. using more or longer than intended, withdrawal symptoms). Childhood victimization was assessed by an affirmative response to any of the following events prior to age 18: being attacked with a weapon; being beaten so as to cause bruises/cuts/broken bones; being forced to participate in sexual acts; being abused emotionally causing very bad feelings. Trauma related to abuse (duration/severity, type/ relation of perpetrator) was queried in six dichotomous items; endorsement of three or more indicated severe abuse-related trauma. Social support was measured using the 19-item MOS Social Support Survey (Sherbourne \& Stewart, 1991), which includes domains of emotional/ tangible/affectionate support and positive social interaction (overall social support alpha reliability $=.92$ ). Scores were transformed to scale of $0-100$ for comparison to published means and dichotomized: 17 (median) and under was considered low social support.

Reporting experiencing severe physical pain in the past 90 days assessed physical pain. Past 90-day sexual risk was assessed dichotomously by (1) having $3+$ sexual partners and (2) having unprotected vaginal sex with a casual partner.

\section{Results}

Descriptive statistics were calculated for variables of interest and demographics and are detailed in Table 1.

Bivariate logistic regression models examined relationships between SMI, demographics, and all independent variables. Measures exhibiting significant predictive values were included in a multivariate logistic regression model, using the backward step likelihood ratio procedure (.05 significance level cutoff). Results are detailed in Table 2. In the bivariate models substance dependence, past 90-day physical pain, having 3+ sexual partners, severe abuse-related trauma, being victimized before the age of 18 and low social support were associated with higher odds of meeting criteria for SMI, while demographics and unprotected vaginal sex were not. In the multivariate model substance dependence, past 90day physical pain, having $3+$ recent sexual partners, severe abuse-related trauma, and low social support retained their significance while childhood victimization did not.

\section{Discussion and conclusions}

Results of this study suggest that young women in the club scene are highly vulnerable, with self-reported rates of SMI far greater than rates in the general population and even substance abusing samples (Johnson, Cunningham-Williams, \& Cottler, 2003). Yet the high levels of interconnected victimization, mental health, pain, substance use and sexual risk factors are underreported, as young women in the club scene appear to be more similar to other marginalized drug-involved populations than previously considered (Buttram et al., 2014; Surratt et al., 2011). Childhood sexual abuse and victimization, more commonly reported by women, are a major risk factors for psychiatric illness, drug dependence and many drug- 
related consequences (Green et al., 2010; McLaughlin et al., 2010). Low social support was linked to SMI, consistent with research highlighting the multiple barriers in access to services (Greenfield, Back, Lawson, \& Brady, 2010).

Women reported high rates of sexual risk behaviors similar to previous studies of substance abusing women (Meade, Kershaw, Hansen, \& Sikkema, 2009). Consistent with an approach examining links between these various factors, prior studies show that abuse-related traumagenic factors were associated with poorer mental health and greater sexual risk among women (Surratt et al., 2011). These sexual risk behaviors, coupled with low social support and limited access to services, have been well-documented in populations with comorbid SMI and substance dependence, placing this population at-risk for contracting sexually-transmitted infections (Meade et al., 2009). Employing a biopsychosocial approach, this study also explored physical pain and found that women reporting significant physical pain had nearly four times higher odds of meeting criteria for SMI, even when controlling for substance dependence. Previous studies have documented the strong link between physiological and psychological pain, particularly within the context of prescription opioid abuse (Jamison et al., 2010) and congruent with the self-medication hypothesis (Jamison et al., 2010; Khantzian, 1997). This is particularly prevalent within populations that have experienced adverse childhood events (Min, Minnes, Kim, \& Singer, 2013). While this finding may not be surprising, considering the high rates of childhood victimization and prescription opioid misuse, to our knowledge this is the first study to examine physical pain as a comorbid factor linked to SMI among this population.

Our study has several limitations. Mental distress symptoms were self-assessed; caution is warranted when generalizing the prevalence of psychological distress in our study compared to studies utilizing clinician-administered interviews. The ability to generalize the findings may be limited by the study eligibility requirements requiring recent substance use (though the sample of women are representative of the racial/ethnic makeup of the county). Finally, the ability to draw causal inferences between is limited by the cross-sectional design. Despite these limitations, it would appear that this out-of-treatment population is in great need of tailored outreach for primary health, mental health and substance abuse treatment services. Research and intervention development should be based on approaches that consider this multifaceted milieu and incorporate a biopsychosocial approach that takes into account biological, psychological and social-structural components (Griffiths, 2009).

Targeted, trauma-based, culturally sensitive multi-level interventions are crucial; mental health outreach efforts, HIV prevention, and interventions specifically targeted to increase social support may be useful. This population appears to be largely disconnected from substance abuse and mental health treatment services, and integration of educational materials, motivational interviewing and other brief interventions into primary care settings, emergency rooms and community clinics should be considered.

Future studies may consider employing gender-based analyses, as many significant differences have been found between men and women that correlate with SMI, substance use, sexual risk behaviors and treatment outcomes. Gender-based analyses are crucial if we are to understand some of the structural issues surrounding young adult club drug use in 
general and the significant role gender plays in this culture in particular, and design appropriate, feasible and effective interventions to reduce risks associated with drug use and risky sexual behavior.

\title{
Acknowledgments
}

\author{
Funding \\ This work was supported by National Institute on Drug Abuse DHHS [grant number 5 R01 DA019048].
}

\section{References}

Buttram, ME., Kurtz, SP. Characteristics associated with group sex participation among men and women in the club drug scene. Sexual Health. 2015. Retrieved from http://www.publish.csiro.au/ paper/SH15071.htm.

Buttram ME, Surratt HL, Kurtz SP. Resilience and syndemic risk factors among African-American female sex workers. Psychology, Health \& Medicine. 2014; 19:442-452.

Dennis ML, Feeney T, Stevens LH, Bedoya L. Global appraisal of individual needs-short screener (GAIN-SS): Administration and scoring manual for the GAIN-SS Version 2.0.1. Bloomington, IL: Chestnut Health Systems. Retrieved February. 2006; 1:2011.

Ferro MA. Major depressive disorder, suicidal behaviour, bipolar disorder, and generalised anxiety disorder among emerging adults with and without chronic health conditions. Epidemiology and Psychiatric Sciences. 2016; 25:462-474. DOI: 10.1017/S2045796015000700 [PubMed: 26347304]

Green JG, McLaughlin KA, Berglund PA, Gruber MJ, Sampson NA, Zaslavsky AM, Kessler RC. Childhood adversities and adult psychiatric disorders in the national comorbidity survey replication I: Associations with first onset of DSM-IV disorders. Archives of General Psychiatry. 2010; 67:113-123. DOI: 10.1001/archgenpsychiatry.2009.186 [PubMed: 20124111]

Greenfield SF, Back SE, Lawson K, Brady KT. Substance abuse in women. Psychiatric Clinics of North America. 2010; 33:339-355. DOI: 10.1016/j.psc.2010.01.004 [PubMed: 20385341]

Greenfield SF, Brooks AJ, Gordon SM, Green CA, Kropp F, McHugh RK, ... Miele GM. Substance abuse treatment entry, retention, and outcome in women: A review of the literature. Drug and Alcohol Dependence. 2007; 86(1):1-21. DOI: 10.1016/j.drugalcdep.2006.05.012 [PubMed: 16759822]

Griffiths M. A 'components' model of addiction within a biopsychosocial framework. Journal of Substance Use. 2009; 10:191-197. DOI: 10.1080/14659890500114359

Jamison RN, Butler SF, Budman SH, Edwards RR, Wasan AD. Gender differences in risk factors for aberrant prescription opioid use. The Journal of Pain. 2010; 11:312-320. DOI: 10.1016/j.jpain. 2009.07.016 [PubMed: 19944648]

Johnson SD, Cunningham-Williams RM, Cottler LB. A tripartite of HIV-risk for African American women: The intersection of drug use, violence, and depression. Drug and Alcohol Dependence. 2003; 70:169-175. DOI: 10.1016/S0376-8716(02)00345-9 [PubMed: 12732410]

Kelly BC, Parsons JT. Prescription drug misuse among club drug-using young adults. The American Journal of Drug and Alcohol Abuse. 2007; 33:875-884. DOI: 10.1080/00952990701667347 [PubMed: 17994483]

Khantzian EJ. The self-medication hypothesis of substance use disorders: A reconsideration and recent applications. Harvard Review of Psychiatry. 1997; 4:231-244. DOI: 10.3109/10673229709030550 [PubMed: 9385000]

Kurtz SP, Buttram ME, Surratt HL. Benzodiazepine dependence among young adult participants in the club scene who use drugs. Journal of Psychoactive Drugs. 2017; 49:39-46. DOI: 10.1080/02791072.2016.1269978 [PubMed: 28001962]

Kurtz SP, Surratt HL, Levi-Minzi MA, Mooss A. Benzodiazepine dependence among multidrug users in the club scene. Drug and Alcohol Dependence. 2011; 119:99-105. DOI: 10.1016/j.drugalcdep. 2011.05.036 [PubMed: 21708434] 
McLaughlin KA, Green JG, Gruber MJ, Sampson NA, Zaslavsky AM, Kessler RC. Childhood adversities and adult psychiatric disorders in the national comorbidity survey replication II: Associations with persistence of DSM-IV disorders. Archives of General Psychiatry. 2010; 67:124-132. DOI: 10.1001/archgenpsychiatry.2009.187 [PubMed: 20124112]

Meade CS, Kershaw TS, Hansen NB, Sikkema KJ. Long-term correlates of childhood abuse among adults with severe mental illness: Adult victimization, substance abuse, and HIV sexual risk behavior. AIDS and Behavior. 2009; 13:207-216. DOI: 10.1007/s10461-007-9326-4 [PubMed: 17968646]

Meade CS, Sikkema KJ. HIV risk behavior among adults with severe mental illness: A systematic review. Clinical Psychology Review. 2005; 25:433-457. DOI: 10.1016/j.cpr.2005.02.001 [PubMed: 15914265]

Min MO, Minnes S, Kim H, Singer LT. Pathways linking childhood maltreatment and adult physical health. Child Abuse \& Neglect. 2013; 37:361-373. DOI: 10.1016/j.chiabu.2012.09.008 [PubMed: 23195701]

Parsells KJ, Cook SF, Kaufman DW, Anderson T, Rosenberg L, Mitchell AA. Prevalence and characteristics of opioid use in the US adult population. Pain. 2008; 138:507-513. DOI: 10.1016/ j.pain.2008.01.027 [PubMed: 18342447]

Remy L, Narvaez J, Sordi A, Guimaraes LS, Von Diemen L, Surratt H, ... Pechansky F. Correlates of unprotected sex in a sample of young club drug users. Clinics. 2013; 68:1384-1391. [PubMed: 24270948]

Sherbourne CD, Stewart AL. The MOS social support survey. Social Science \& Medicine. 1991; 32:705-714. DOI: 10.1016/0277-9536(91)90150-B [PubMed: 2035047]

Simoni-Wastila L. The use of abusable prescription drugs: The role of gender. Journal of Women's Health \& Gender-Based Medicine. 2000; 9:289-297.

Surratt HL, Kurtz SP, Chen M, Mooss A. HIV risk among female sex workers in Miami: The impact of violent victimization and untreated mental illness. AIDS Care. 2011; 24:553-561. DOI: 10.1080/09540121.2011.630342 [PubMed: 22085330]

Wechsberg W. Promising international interventions and treatment for women who use and abuse drugs: Focusing on the issues through the In Women's Group. Substance Abuse and Rehabilitation. 2012; 3:1-4. DOI: 10.2147/SAR.S21291 


\section{Table 1}

Demographics, drug use, sexual behaviors, health and social risk factors of young adult women multidrug users $(N=222)$.

\begin{tabular}{|c|c|c|}
\hline & $N$ & $\%$ \\
\hline \multicolumn{3}{|l|}{ Demographics } \\
\hline Ages 24 and younger & 129 & 58.1 \\
\hline \multicolumn{3}{|l|}{ Race/ethnicity } \\
\hline Hispanic/Latino & 140 & 63.1 \\
\hline Black/African American & 50 & 22.5 \\
\hline White/Caucasian & 26 & 11.7 \\
\hline Other race/ethnicity & 6 & 2.7 \\
\hline Heterosexual identity & 130 & 58.6 \\
\hline More than a high school education & 118 & 53.2 \\
\hline \multicolumn{3}{|l|}{ Past 90-day drug use } \\
\hline Alcohol & 220 & 99.1 \\
\hline Ecstasy & 214 & 96.4 \\
\hline Marijuana & 213 & 95.9 \\
\hline Cocaine & 203 & 91.4 \\
\hline Other hallucinogens & 111 & 50.0 \\
\hline LSD & 93 & 41.9 \\
\hline Crack cocaine & 63 & 28.4 \\
\hline Heroin & 44 & 19.8 \\
\hline Methamphetamine & 42 & 18.9 \\
\hline GHB & 35 & 15.8 \\
\hline Rx sedatives & 203 & 91.4 \\
\hline Rx opioids & 202 & 91.0 \\
\hline Rx stimulants & 118 & 53.2 \\
\hline Rx antipsychotics & 64 & 28.8 \\
\hline $\mathrm{Rx}$ antidepressants & 56 & 25.2 \\
\hline Injection drug use & 29 & 13.1 \\
\hline \multicolumn{3}{|l|}{ Past 90-day sexual behaviors } \\
\hline Monogamous relationship 4+ months & 71 & 32.0 \\
\hline Unprotected vaginal sex - casual partner & 139 & 62.6 \\
\hline $3+$ sexual partners & 93 & 41.9 \\
\hline \multicolumn{3}{|l|}{ Health and social risk factors } \\
\hline DSM IVR substance dependence & 145 & 65.3 \\
\hline Physical pain high (past 90-days) & 86 & 38.7 \\
\hline Victimized before age 18 & 133 & 59.9 \\
\hline Severe abuse-related trauma & 107 & 48.2 \\
\hline DSM IVR severe mental illness & 134 & 60.4 \\
\hline
\end{tabular}

Psychol Health Med. Author manuscript; available in PMC 2019 January 01. 


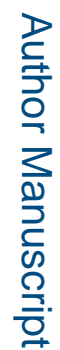

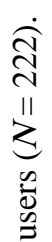

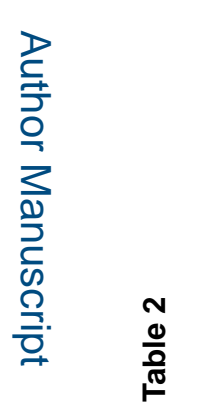

哭

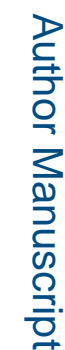

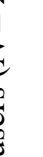

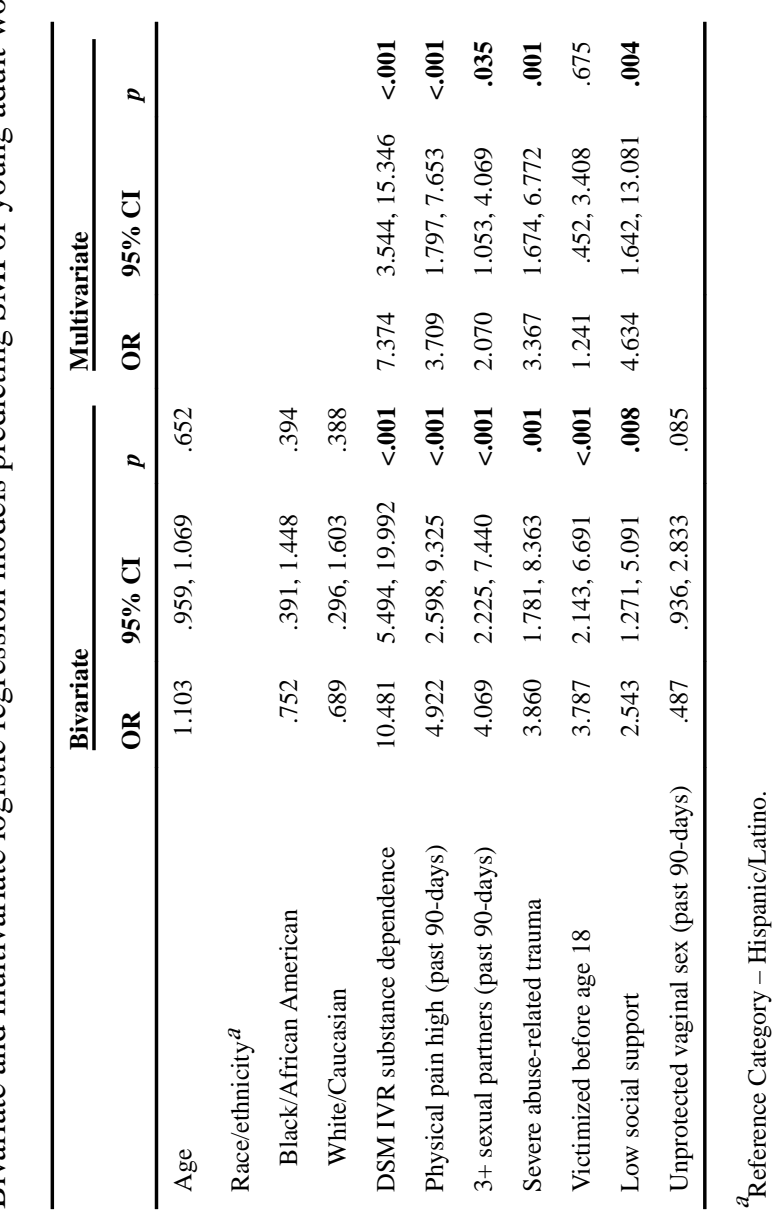

Psychol Health Med. Author manuscript; available in PMC 2019 January 01. 